American Journal of Pharmaceutical Education 2016; 80 (7) Article 117.

\title{
RESEARCH
}

\section{Net Income of Pharmacy Faculty Compared to Community and Hospital Pharmacists}

\author{
Marie A. Chisholm-Burns, PharmD, MPH, MBA, Justin Gatwood, PhD, MPH, Christina A. Spivey, PhD, \\ Susan E. Dickey, PharmD \\ University of Tennessee College of Pharmacy, Memphis, Tennessee \\ Submitted July 8, 2015; accepted September 23, 2015; published September 25, 2016.
}

\begin{abstract}
Objective. To compare the net cumulative income of community pharmacists, hospital pharmacists, and full-time pharmacy faculty members (residency-trained or with a $\mathrm{PhD}$ after obtaining a PharmD) in pharmacy practice, medicinal chemistry, pharmaceutics, pharmacology, and social and administrative sciences.

Methods. Markov modeling was conducted to calculate net projected cumulative earnings of career paths by estimating the costs of education, including the costs of obtaining degrees and student loans.

Results. The economic model spanned 49 years, from ages 18 to 67 years. Earning a PharmD and pursuing an academic career resulted in projected net cumulative lifetime earnings ranging from approximately $\$ 4.7$ million to $\$ 6.3$ million. A pharmacy practice faculty position following public pharmacy school and one year of residency resulted in higher net cumulative income than community pharmacy. Faculty members with postgraduate year 1 (PGY1) training also had higher net income than other faculty and hospital pharmacy career paths, given similar years of prepharmacy education and type of pharmacy school attended. Faculty members with either a PharmD or PhD in the pharmacology discipline may net as much as \$5.9 million and outpace all other $\mathrm{PhD}$ graduates by at least $\$ 75000$ in lifetime earnings. Projected career earnings of postgraduate year 2 (PGY2) trained faculty and PharmD/PhD faculty members were lower than those of community pharmacists. Findings were more variable when comparing pharmacy faculty members and hospital pharmacists.

Conclusion. With the exception of PGY1 trained academic pharmacists, faculty projected net cumulative incomes generally lagged behind community pharmacists, likely because of delayed entry into the job market as a result of advanced training/education. However, nonsalary benefits such as greater flexibility and autonomy may enhance the desirability of academic pharmacy as a career path.
\end{abstract}

Keywords: academic pharmacy, financial analysis, net income

\section{INTRODUCTION}

The doctor of pharmacy (PharmD) degree opens the door to a variety of pharmacy career paths, with community pharmacy being one of the most visible to the general public, as $54 \%$ of actively practicing pharmacists are employed in this area. ${ }^{1}$ In addition to this traditional pharmacy career, options available to pharmacists include practice in hospital pharmacy, ambulatory care, and numerous other areas. ${ }^{2,3}$ Another career option for pharmacists is academic pharmacy.

Corresponding Author: Marie A. Chisholm-Burns, University of Tennessee College of Pharmacy, 881 Madison Ave., Suite 264, Memphis, TN 38163. Tel: 901-448-7141. Fax: 901-448-7053. E-mail: mchisho3@uthsc.edu
Academic pharmacists typically are full-time faculty employees in colleges or schools of pharmacy who have responsibilities in the areas of teaching, service, and scholarship. Career tracks within academia can focus on pharmacy practice, pharmaceutical sciences, or the social, economic, behavioral, or administrative areas of pharmacy. ${ }^{4}$ Benefits of a career in academic pharmacy are numerous, including autonomy of faculty members, which is the strongest motivator to pursue a career in academic pharmacy. ${ }^{5}$ This characteristic is unmatched by other pharmacy career paths and allows for more flexible and diverse work experiences. Additionally, the academic environment provides the distinct ability to shape the future of the pharmacy profession, to create 


\section{American Journal of Pharmaceutical Education 2016; 80 (7) Article 117.}

and disseminate knowledge through scholarship, and to train and mentor pharmacy and graduate students and pharmacists, including residents and fellows. ${ }^{4,6}$ Other benefits of an academic pharmacy career may include tangibles such as tuition reimbursement and/or tuition reduction for self and family, excellent fringe benefits (eg, pension/retirement plans), and the possibility of student loan forgiveness.

Despite the benefits of a career in academic pharmacy, it is underpursued by pharmacists - a concern given the growing need for pharmacy faculty members. Since 2000, more than 50 new schools of pharmacy have opened their doors, requiring an increasing number of faculty members. Consequently, the expansion of existing programs, creation of new programs, and accreditation standards stating that schools must have "a sufficient number of faculty members to effectively address" teaching, research, and service needs have placed additional demands on the market for pharmacy faculty members. ${ }^{7-9}$ The need for additional training (eg, completing residency training or a graduate degree) and lower starting salaries are often cited as motivators that drive pharmacists away from academia. ${ }^{10-12}$ However, the literature is scarce regarding the long-term economic impact of a career in academic pharmacy compared to other pharmacy career paths.

In the only published study found, Hagemeier and Murawski conducted an economic analysis of those who earn a doctor of philosophy (PhD) degree after completion of a PharmD. ${ }^{13}$ In this study, salary data from 2008 were used to determine the net present value and internal rate of return for earning a $\mathrm{PhD}$ after completing a PharmD, and then entering academic careers commonly associated with the $\mathrm{PhD} .{ }^{13}$ These career paths were compared to pharmacists entering community pharmacy practice directly after completion of the PharmD degree. Investigators found the net present value of salary for $\mathrm{PhD}$ career tracks to be less than that of community pharmacist careers. This analysis suggested that graduate training and subsequent careers in academic pharmacy were not as economically beneficial as a career in community pharmacy. However, this study did not consider other career paths such as hospital pharmacy nor did it examine the economic impact of obtaining a $\mathrm{PhD}$ vs residency training as prerequisites for a career in academic pharmacy. The purpose of this study was to compare the projected net cumulative income of full-time pharmacy faculty members, community pharmacists, and hospital pharmacists with or without residency training.

\section{METHODS}

Markov modeling was conducted to analyze the projected net cumulative earnings (gross cumulative career earnings minus expenditures for postsecondary education) of the following career paths from age 18 to 67 (official age of retirement per the US Social Security Administration ${ }^{14}$ ): community pharmacy; hospital pharmacy without residency training; hospital pharmacy with postgraduate year 1 (PGY1) training; hospital pharmacy with PGY1 and postgraduate year 2 (PGY2) training; academic pharmacy with residency training (PGY1 only or PGY1 plus PGY2) and appointed in pharmacy practice department; and academic pharmacy with a PharmD and $\mathrm{PhD}$ and appointed in department (or division/discipline) of medicinal chemistry, pharmacy practice, pharmaceutics, pharmacology, or social and administration sciences.

Net cumulative earnings were determined using estimated costs of education and gross salaries. Values from 2014 were used but all figures were not reverted back to these dollars as that would have discounted future incomes. The analysis focused on providing raw values without discounting for future values as the timing of the inflows/outflows are person-specific. Similar to previous analyses, employment in hospital or community (retail) pharmacy settings was included in the model because they represent the primary pharmacy job sectors, and salaries in these settings are well documented. ${ }^{11,15}$ Table 1 provides a list of model inputs, and all analyses were conducted using TreeAge Pro Healthcare, v2014 (TreeAge Software, Inc., Williamstown, MA). ${ }^{11,16-28}$

Markov modeling began at age 18 at which point higher education costs and income began to accumulate. The costs of postsecondary and pharmacy school education were calculated for students who completed either three or four years of prepharmacy education. Therefore, depending on years of prepharmacy education, pharmacists were assumed to graduate from pharmacy school at either 25 or 26 years of age. At the point of graduation, they either entered the job market immediately, pursued residency training for one or two years, or continued on to complete a $\mathrm{PhD}$ in pharmacology, pharmaceutics, medicinal chemistry, or social and administrative sciences. As a result, the analysis compared projected lifetime earnings from pharmacy careers in community pharmacies, hospitals (with and without residency training), or academic settings (with a PharmD/PhD or PharmD followed by one or two years of residency).

Annual Markov cycles were conducted for each career option. The models for PharmD graduates reflected the stage of employment for each career path: in school or training, early career, and experienced worker. For academic career paths, the modeling also included the traditional progression through the tenure and promotion process. Individuals were assumed to have remained in 
American Journal of Pharmaceutical Education 2016; 80 (7) Article 117.

Table 1. Markov Model Inputs ${ }^{11,16-28}$

\begin{tabular}{|c|c|c|}
\hline Variable & Value & References \\
\hline \multicolumn{3}{|l|}{$\overline{\text { Income }(\$)^{\mathrm{a}, \mathrm{b}}}$} \\
\hline \multicolumn{3}{|l|}{ PharmD Graduates Only (\$) } \\
\hline Hospital Pharmacists & 99840 & 11 \\
\hline \multirow[t]{2}{*}{ Pharmacy Residents } & 42000 (PGY1) & 16 \\
\hline & $50000(\mathrm{PGY} 2)$ & \\
\hline Academic Pharmacist (PharmD/ PGY2; Pharmacy Practice) & 98657 & 17 \\
\hline \multicolumn{3}{|l|}{ PharmD/PhD Graduates $(\$)$} \\
\hline Pharmacy Practice & 98657 & 17 \\
\hline Pharmacology & 87657 & 17 \\
\hline Medicinal Chemistry & 87719 & 17 \\
\hline Annual Raise $(\%)$ & 2.9 & 19 \\
\hline Cost-of-Living Adjustment (\%) & 1.5 & 20 \\
\hline \multicolumn{3}{|l|}{ Educational Costs $(\$)$} \\
\hline \multicolumn{3}{|l|}{ Immediate (Annual) Costs $^{\mathrm{c}}$} \\
\hline Undergraduate $^{\mathrm{d}}$ & 23066 & 21 \\
\hline Public Pharmacy School & 18713 & 22 \\
\hline Private Pharmacy School & 32967 & 22 \\
\hline Cost of Living & 22287 & $\begin{array}{l}\text { Communication University of Tennessee } \\
\text { Office of Financial Aid February } 2014\end{array}$ \\
\hline \multicolumn{3}{|l|}{ Student Loans } \\
\hline Public Pharmacy School & 103829 & 23 \\
\hline \multicolumn{3}{|l|}{ Pharmacy School Graduate Positions (\%) } \\
\hline \multirow[t]{2}{*}{ Community Job } & 56.3 (public) & 23 \\
\hline & 59.4 (private) & \\
\hline \multirow[t]{2}{*}{ Hospital Job } & 24.0 (public) & 23 \\
\hline & 25.2 (private) & \\
\hline \multirow[t]{2}{*}{ PGY1 Residency } & 19.7 (public) & Calculated from communication with \\
\hline & 15.4 (private) & ASHP January 2014 \\
\hline \multirow[t]{2}{*}{ PGY2 Residency } & 16.9 (public) & Calculated from communication with \\
\hline & 11.3 (private) & ASHP January 2014 \\
\hline \multicolumn{3}{|l|}{ Unemployment Rate (\%) } \\
\hline Pharmacy Degree Holders & 3.2 & 26 \\
\hline \multicolumn{3}{|l|}{ Length of Unemployment (weeks) ${ }^{\mathrm{e}}$} \\
\hline Doctoral Degree Holders & 18.7 & 27,28 \\
\hline
\end{tabular}

ASHP $=$ American Society of Health-System Pharmacists

${ }^{\mathrm{a}}$ Values listed are starting salaries

${ }^{\mathrm{b}}$ In the model analysis, PharmD holders were assumed to: (1) graduate from $3+4$ programs and enter the job market at age 25 (age 26 if completing a PGY1 residency, age 27 if completing a PGY2 residency); (2) graduate from 4+4 programs and enter the job market at age 26 (age 27 if completing a PGY1 residency, age 28 if completing a PGY2 residency); and (3) graduate from $\mathrm{PhD}$ programs at age 30 (if previously graduated from a $3+4$ PharmD program) or 31 (if previously graduated from a $4+4$ PharmD program) ${ }^{c}$ Represents national average annual costs

${ }^{\mathrm{d}}$ Includes room and board and is the national average across all (public and private) 4-year undergraduate institutions

${ }^{\mathrm{e}}$ Refers to the average number of weeks between jobs if an individual loses a job in a given year (data for specific degree fields were not available) 


\section{American Journal of Pharmaceutical Education 2016; 80 (7) Article 117.}

the same career path after entering the job market to simplify the model.

At the base of the model, an individual could have chosen to attend college for either three or four years of undergraduate study, as required for acceptance by most schools of pharmacy [according to the American Association of Colleges of Pharmacy (AACP)], followed by four years of pharmacy school at either a public or private institution. ${ }^{29}$ Four-year PharmD programs were modeled, as the majority of pharmacy schools have a traditional 4-year curriculum. The most popular postpharmacy school employment options were modeled: community or hospital pharmacy practice or the pursuit of a 1- or 2-year residency followed by hospital employment. Building off of this analysis, the option to enter an academic position was inserted in two places. First, the pursuit of a $\mathrm{PhD}$ degree was included following obtainment of a PharmD. Modeled after the study by Hagemeier and Murawski, we assumed the $\mathrm{PhD}$ degree would be obtained after five years in a graduate program and that direct entry into an assistant professorship was available. ${ }^{13}$ For study purposes, five pharmacy disciplines were modeled based on data collected by AACP: ${ }^{17}$ pharmacy practice, social and administrative sciences (SAS), pharmacology, medicinal chemistry, and pharmaceutics. The second point of entry to an academic pharmacy career was modeled after completing residency training (either PGY1 only or PGY1 plus PGY2), at which point the trainee would assume an assistant professorship in pharmacy practice. To model the progression from entry through the promotion process, it was assumed that six years was required to move from assistant to associate professor and from associate to full professor (12 years in total). ${ }^{13}$ Once the individual achieved full professorship, they were assumed to remain in that role until reaching 67 years of age so that fair comparisons could be made between academic and practice-based career paths.

Annual income across each career path until age 67 was used as a model paramenter to demonstrate the benefits of pursuing a career in pharmacy. Stipend rates for those opting to pursue a $\mathrm{PhD}$ were based on values defined by National Research Service Awards, as dictated by the National Institutes of Health. ${ }^{18}$ Salaries for residents were accounted for in the model using figures from the American College of Clinical Pharmacy. ${ }^{16}$ Income values and percent increases at promotion for faculty members were derived from AACP's Profile of Pharmacy Faculty report and were distributed by discipline and faculty level using reported mean values for calendar year appointments across both public and private pharmacy schools. ${ }^{17}$ Starting salaries were based on those reported for faculty members within each discipline with $0-1$ years of experience after which they received the average yearly increase reported for assistant professors for the subsequent five years. After six years, promotion was assumed and salaries reflected the mean percent increase for associate professors with 0-1 years of experience; the average yearly increase across all associate professors was used for the five years thereafter. Once full professorial rank was attained, the average yearly increase for the first year was again used; however, in years thereafter, only a $1.5 \%$ cost of living adjustment was used, similar to the strategy employed to model practice-based pharmacists on other career paths.

The methods to model cumulative income trajectory for practice-based pharmacists are reported elsewhere; however, a brief explanation follows. ${ }^{15}$ For the first five years after graduation (early career), the model gave practice-based pharmacists the national average salary increase of $2.9 \%$. After five years, salaries were increased to the average "experienced" level and thereafter received the national average salary increase. ${ }^{19}$ Salaries were capped after 10 years, and only national average cost of living increases $(1.5 \%)$ were factored into income data to account for inflation. ${ }^{20}$

To determine the total cost of undergraduate attendance based on number of years enrolled, national average amounts for college tuition and room and board from 2012 were used. ${ }^{21}$ The difference between the total cost of attendance for each year (\$23066) and the total average amount borrowed (\$29 400) divided by 4 (\$7350) determined the immediate annual cost of undergraduate attendance $(\$ 15716) .{ }^{24}$ For students completing only three years of college prior to pharmacy school, total immediate costs and amount borrowed were reduced by $25 \%$ as follows: total immediate costs $(\$ 15176 \times 3$ years $=\$ 45528)$ and amount borrowed $(\$ 29400 \times 0.75=\$ 22050)$. For public and private pharmacy schools, national average tuition and student loan amounts were provided by AACP, with cost of living included in the total cost of attendance (Table 1). ${ }^{22,23}$ The difference between the average amount borrowed and the total cost of attendance was assumed to be immediately absorbed by the student, resulting in net negative benefits for the years spent in college and pharmacy school.

Student loan repayment was factored into the determination of net benefits to account for long-term education costs. Cost of education was modeled as the sum of subsidized loans for undergraduate studies (at maximum total amounts of $\$ 13500$ for three years of prepharmacy and $\$ 19000$ for four years of prepharmacy), unsubsidized loans for undergraduate studies (in the total amounts of $\$ 8550$ for three years of prepharmacy and \$10 400 for four years of prepharmacy, which 


\section{American Journal of Pharmaceutical Education 2016; 80 (7) Article 117.}

supplemented subsidized loans to the mean amount borrowed per year), unsubsidized loans for pharmacy school (maximum amount allowed of $\$ 20500$ per year), and PLUS loans for pharmacy school (in the total amounts of $\$ 21828$ for public pharmacy school and $\$ 60848$ for private pharmacy school, which supplemented unsubsidized loans to the mean amount borrowed). Undergraduate loans, both subsidized and unsubsidized, had interest rates of $4.66 \%$, while graduate unsubsidized loans had an interest rate of $6.21 \%$ and graduate PLUS loans carried a rate of $7.21 \%{ }^{25}$ Among pharmacy graduates, the total amount borrowed during either seven or eight years of postsecondary education was used to determine the monthly payment, with repayment over 25 years. ${ }^{30}$ For pharmacy graduates who pursued residency training, loans were assumed to be in forbearance, with interest accruing at the aforementioned interest rates for the one or two years spent in residency training. For modeling purposes, those opting to pursue a $\mathrm{PhD}$ had their undergraduate and pharmacy school loans deferred while enrolled in accordance with federal borrowing policies related to student loans and additional higher education. ${ }^{31}$ While in deferment, interest accrues on unsubsidized and PLUS loans, but not subsidized loans. Repayment of these loans begins in the year following degree completion. As is customary for most doctoral programs, in the model there were no costs of attendance accrued for students in $\mathrm{PhD}$ programs ${ }^{13}$ therefore, the total amount repaid after completing this degree was equal to the amount accumulated by the end of pharmacy school plus accrued interest. Similar to pharmacy graduates pursuing residencies, the repayment period was assumed to be 25 years.

\section{RESULTS}

The economic model spanned 49 years, from age 18 to 67 years. Earning a PharmD and pursuing an academic career resulted in projected net cumulative lifetime earnings ranging from approximately $\$ 4.7$ million, at a minimum, to $\$ 6.3$ million. Table 2 displays the net cumulative incomes of the pharmacy career paths modeled based on years of prepharmacy education (three or four) and type of pharmacy school attended (public or private). A pharmacy practice faculty position following one year of residency resulted in the highest net cumulative income of all career paths modeled, particularly if public pharmacy school was attended. Compared to colleagues opting to complete $\mathrm{a} \mathrm{PhD}$ and entering academic pharmacy in pharmacy practice, those having undergone any residency training net, at a minimum, over half a million dollars more over the course of their career. Pharmacists choosing to complete a $\mathrm{PhD}$ and work in the pharmacology discipline may net as much as \$5.9 million and outpace all other $\mathrm{PhD}$ graduates by at least $\$ 75000$ in lifetime earnings. However, their career earnings were at least \$206 000 lower than residency-trained faculty members, given comparable prepharmacy education and type of pharmacy school. Among $\mathrm{PhD}$ graduates, those entering pharmaceutics could expect to net the lowest cumulative earnings by at least $\$ 275000$, because of lower average yearly salary increases compared to other PhD graduates. ${ }^{17}$ In sum, the cost of three additional years of training - by pursuing a $\mathrm{PhD}$ — could result in over \$1 million in lower projected cumulative income over the course of a pharmacist's career, depending on the discipline chosen and costs accrued during college and pharmacy school (Figures 1 and 2).

As displayed in Figure 1, community pharmacists and PGY1 trained pharmacy faculty members had highly

Table 2. Net Cumulative Incomes of Pharmacy Career Paths

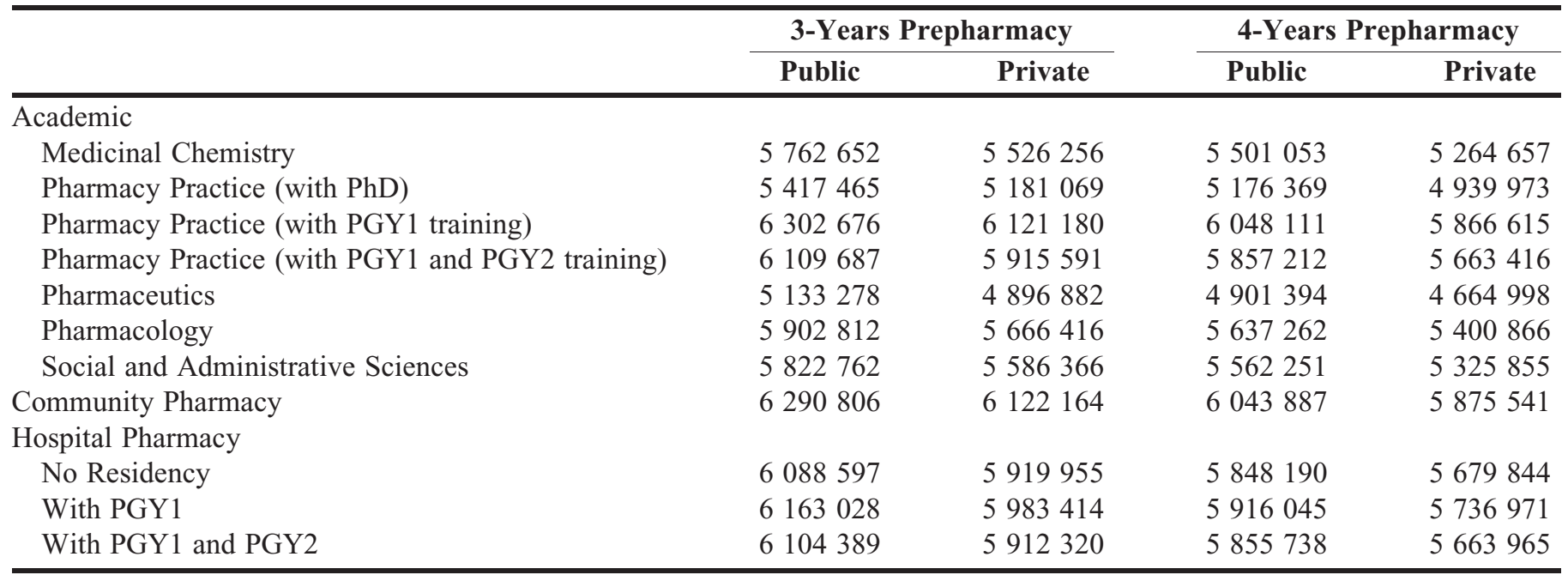




\section{American Journal of Pharmaceutical Education 2016; 80 (7) Article 117.}

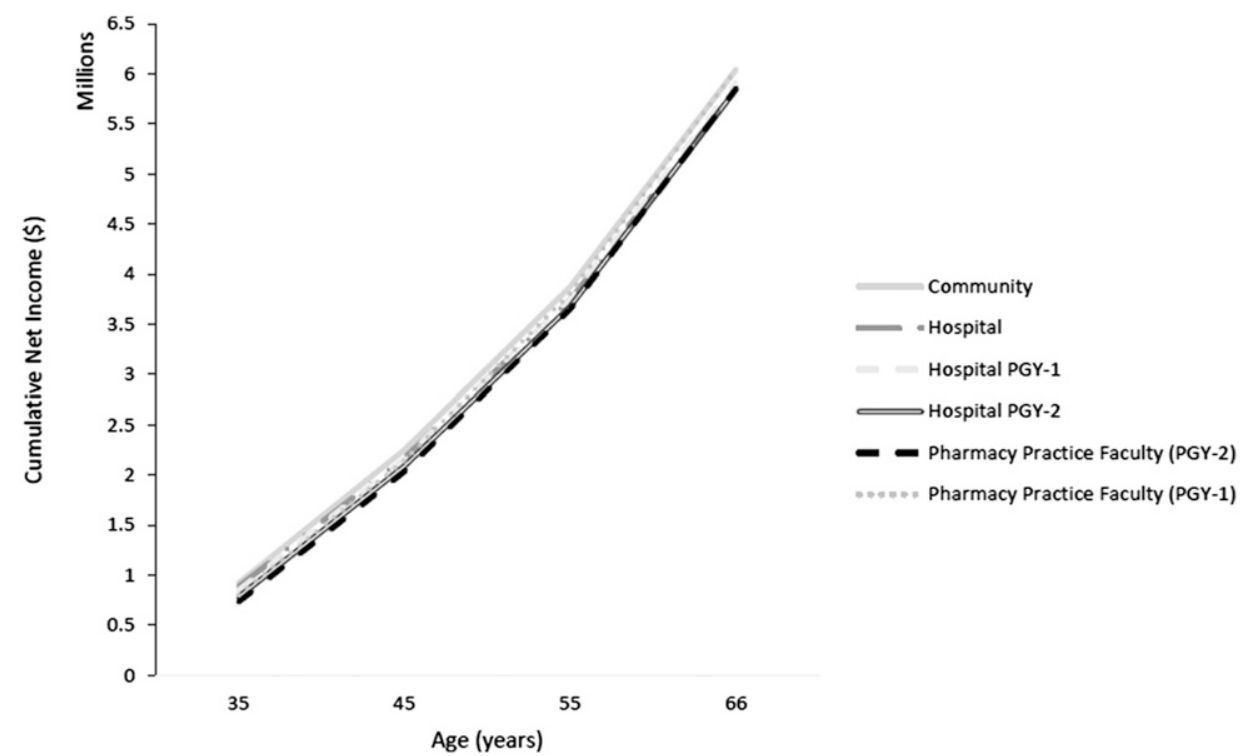

Figure 1. Cumulative Income Trajectory of Pharmacy Practitioners and Faculty Members.

Note: the economic models presented in this study are based on assumptions described herein; as conditions are subject to variability these models should not be used to forecast or guarantee future earnings. This figure compares the income trajectories of community pharmacists hospital pharmacists with no residency training, hospital pharmacists with PGY1 training (referred to as Hospital PGY1), hospital pharmacists with PGY1 and PGY2 training (referred to as Hospital PGY2), pharmacy practice faculty members who have completed a PharmD degree and PGY1 and PGY2 residency training, and pharmacy practice faculty members who have completed a PharmD degree and PGY1 residency training.

similar income trajectories, with PGY1 trained faculty members earning approximately $\$ 3000$ more over the course of their careers. More specifically, pharmacists assuming an academic position following one year of residency out earned all other career options if they chose to attend a public pharmacy school (Table 2). For those PGY1 trained faculty members who attended private schools, income exceeded that of hospital pharmacists with and without residency training, but marginally lower career cumulative incomes were observed compared to community pharmacists. Pharmacists with PGY2 training in academic positions had lower net cumulative earnings compared to community pharmacists as well as those in hospital positions following a PGY1 residency. In the latter example, the projected cumulative lifetime cost of an additional year of training ( PGY2 residency) and taking an academic position was approximately $\$ 53000$ at a minimum. At least $\$ 9000$ more in net cumulative career earnings were realized when residency-trained pharmacy faculty members were compared to their colleagues entering a hospital position immediately following graduation from a public pharmacy school. However, PGY2 pharmacy faculty never closed the gap in earnings compared to colleagues entering a hospital position immediately following graduation from a private pharmacy school (Table 2). Pharmacy faculty who were PGY2 trained had approximately $\$ 550$ less to $\$ 5300$ more in net cumulative lifetime earnings compared to those hospital pharmacists with both PGY1 and PGY2 training, depending on years of prepharmacy education and type of pharmacy school.

\section{DISCUSSION}

Previous research examined the economic outcomes of careers in two of the most popular areas of pharmacy practice (community and hospital pharmacy), but current literature provides little insight into the economic potential of other pharmacy career paths, such as academia. ${ }^{15}$ To better understand the long-term economic impact of a career in academic pharmacy, the current analysis examined the lifetime projected earnings of pharmacy faculty members compared to those of community and hospital pharmacists. Parameters for length of education (three or four years prepharmacy), type of pharmacy school (public or private), postPharmD residency training and $\mathrm{PhD}$ obtainment, and pharmacy career path were considered. With the exception of PGY1 trained faculty members, net cumulative earnings of pharmacy faculty members generally fell short of career earnings of community pharmacists given comparable years of prepharmacy education and type of pharmacy school, with pharmacy faculty members earning approximately $\$ 181000$ to $\$ 212000$ less 


\section{American Journal of Pharmaceutical Education 2016; 80 (7) Article 117.}

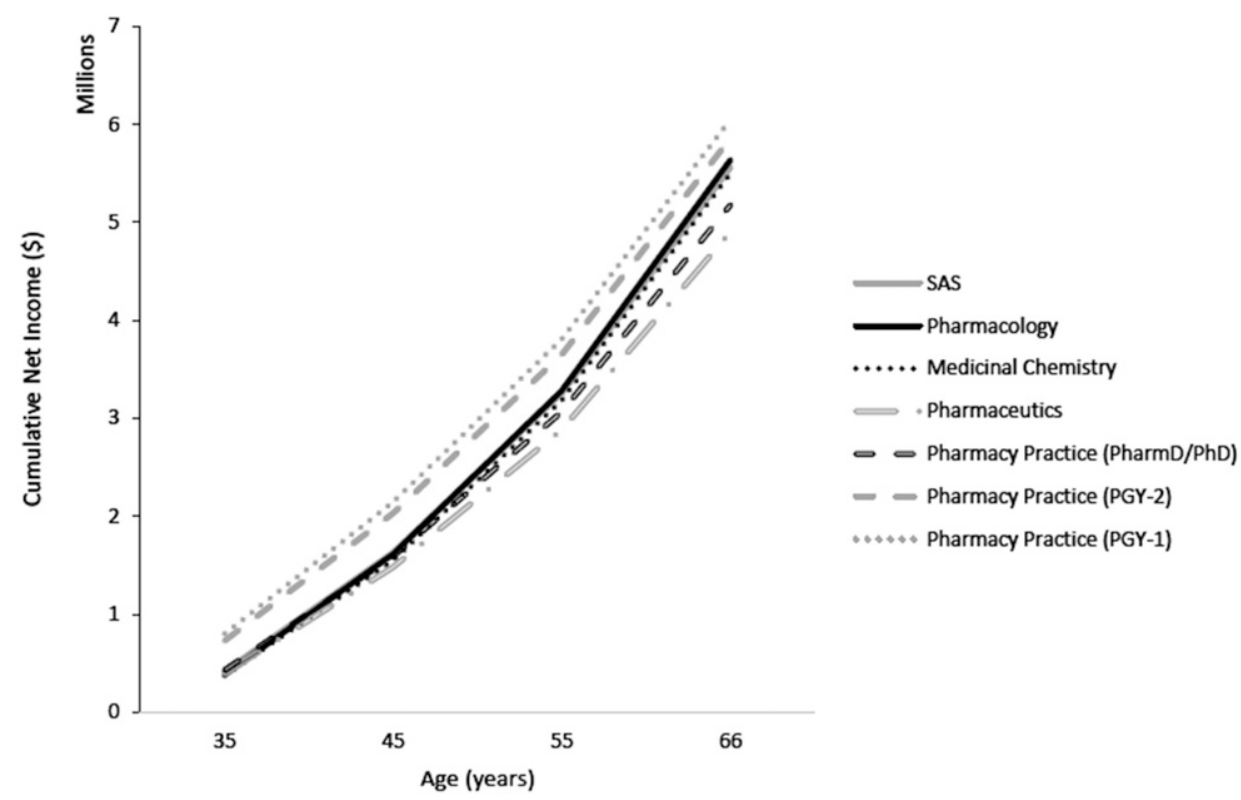

Figure 2. Cumulative Net Income Trajectory of Academic Pharmacy Careers.

Earnings are net the immediate and long-term costs of education. Of the seven academic pharmacy career trajectories modeled two were faculty positions in pharmacy practice following completion of a PharmD degree and PGY1 only or PGY1 plus PGY2 residencies, referred to as pharmacy practice (PGY1) or pharmacy practice (PGY2), respectively. The remaining five trajectories followed completion of a PharmD degree and a PhD degree and were in the departments of medicinal chemistry, pharmacy practice, pharmaceutice, pharmacology, and social and administrative sciences (SAS).

than community pharmacists over the course of a career. Interestingly, PGY1-trained faculty members may earn greater net cumulative income than their peers in community pharmacy provided they attended a public pharmacy school. This is likely a result of: (1) lower costs associated with attending a public pharmacy school compared to a private school; and (2) greater salary growth as the faculty member is promoted through the academic ranks.

Differences in earnings among pharmacy faculty members and practice-based pharmacists are likely attributable to the delayed entry of pharmacy faculty members into the job market because of the need for advanced training/education to qualify for a faculty position. Thus, pharmacists opting to enter the job market later typically had lower net cumulative incomes and lower incomes at younger ages, largely a result of fewer employable years. Consequently, all $\mathrm{PhD}$ faculty career paths had lower net cumulative earnings than community and hospital pharmacists (with and without residency training), given comparable years of prepharmacy education and type of pharmacy school. Findings varied more when comparing the earning potential of PGY2-trained pharmacy faculty members and hospital pharmacists. The former may earn anywhere from $\$ 73000$ less than to $\$ 21000$ more than hospital pharmacists, depending on years of residency training completed by hospital pharmacists. Thus, their projected cumulative career incomes are similar.

Although salary is significant when examining the value of a career, it is not the only consideration, and indeed, individuals often choose to pursue advanced education (eg, $\mathrm{PhD}$ ), training (eg, residency training), and/or careers such as academia for purposes other than salary. For example, academic pharmacy faculty members who achieve tenure are granted a high level of job security not often found in other sectors. A career in academic pharmacy provides extensive flexibility compared to other pharmacy career paths, allowing for pursuit of individual interests in research initiatives, didactic and experiential teaching, patient care, committee work, and involvement in professional organizations. Coupled with the flexibility of this career path is the appeal of the high level of autonomy through which academicians are granted independence in decisionmaking, responsibility, and self-discipline. ${ }^{5}$ Additionally, an academic career fosters creativity and provides an ideal environment for academicians to develop and share their professional passions. Practitioners are also drawn to this path by the opportunities for mentorship and scholarship as well as the ability to play a role in shaping the future of the profession through education and training of student pharmacists. 


\section{American Journal of Pharmaceutical Education 2016; 80 (7) Article 117.}

In addition to the nonmonetary benefits of academia, this career path provides unique financial benefits beyond base salary, such as tuition reimbursement, tuition reduction for self and/or family members, and fringe benefits (eg, pension/retirement plans). Additionally, academic institutions may offer "incentive" plans wherein faculty members may be eligible for an annual salary enhancement (not included in base salary) based on their level of productivity. The use of these bonuses should be considered and used to financially incentivize faculty members.

The American Pharmacists Association (APhA) Career Pathway Evaluation Program surveyed pharmacists and determined factors that most closely aligned to a career in academic pharmacy. ${ }^{32,33}$ Of 48 factors included in the survey, highest scores for academic pharmacy included opportunities for professional involvement, benefits (higher number of paid days off, retirement/pension plans), professional prestige, self-worth, autonomy, the variety of daily activities, application of medical knowledge, parental leave opportunities, and leadership development opportunities. While academic pharmacy may not in general be economically superior to traditional pharmacy career paths when considering cumulative earnings over the lifetime of a career, these additional benefits can be considered when choosing a career path. Additionally, many of these benefits can be economically quantified; for example, fringe benefits in academia tend to equal more than $30 \%$ of base salary. Greater emphasis and exposure of these tangible and intangible benefits may help augment the pipeline of potential pharmacy faculty members as well as bolster faculty recruitment and retention efforts.

As with any study, there were limitations. The findings of the analysis depend on the validity of the data used to create study models; however, data for model inputs were collected from well-established, reliable sources. As a result, the data and models used were valid under these assumptions: pharmacists and academicians remained in the same career path after entering the job market and remained in that role until age 67; $\mathrm{PhD}$ degrees were obtained after five years in graduate programs; direct entrance into an assistant professorship was available upon degree completion; academicians progressed from assistant to associate and full professorship in the timeframe described; and graduate student loan repayment was completed over an extended 25-year period. The dependence on data validity and the variations in career path and earnings that occur in real life are common limitations in economic models that are accepted under the described conditions and interpreted under these assumptions. The economic models presented in this study are based on assumptions described herein; as conditions are subject to variability, these models should not be used to forecast future earnings nor are these earnings guaranteed. An additional limitation is that we specifically focused on PharmD/PhD holders, rather than those who opted to solely pursue the $\mathrm{PhD}$ degree. This was done because the purpose of the study was to examine projected net earnings of individuals who obtained a PharmD, received additional training (residencies) or education $(\mathrm{PhD})$, and then pursued an academic pharmacy career. Because of the focus on PharmD/PhD holders, a subsequent limitation is the salary data used in the analysis. More specifically, the data source (AACP) for pharmacy faculty salaries does not differentiate between faculty members who have both a PharmD/PhD and those PhDs who do not have a PharmD. ${ }^{17}$ Because it is typical for $\mathrm{PhD}$ faculty members in medicinal chemistry, pharmacology, pharmaceutics, and SAS to not have a PharmD (as Hagemeier and Murawski noted, approximately $10 \%$ of graduate students enrolled in pharmacy $\mathrm{PhD}$ programs also had a PharmD degree ${ }^{13}$ ), the data may not truly be reflective of the salaries of PharmD/ $\mathrm{PhD}$ faculty members. Also, these data do not include bonuses or other salary incentives. More generally, the data are limited in that they do not have distribution values and, as a result, we were unable to perform sensitivity analysis.

The models presented in this study project lifetime career earnings for PGY1-trained pharmacy academicians that are comparable to community pharmacists but surpass hospital pharmacists, while PGY2-trained pharmacy academicians have earnings comparable to residency-trained hospital pharmacists but somewhat less comparable to community pharmacists. The models further suggest that residency-trained pharmacy faculty members may have higher net earnings than PharmD/ $\mathrm{PhD}$ faculty members. With changes in the distribution of tenure-track faculty members in recent years, future economic analyses of academic pharmacy should address the effects of tenure vs nontenure status on economic outcomes. $^{34}$

\section{CONCLUSION}

The findings of this economic evaluation demonstrate that, under the described assumptions, projected net cumulative incomes of PGY1-trained pharmacy faculty members are higher than all other pharmacy career paths modeled. However, other pharmacy faculty members (PGY2-trained and PharmD/PhD) have lower net cumulative incomes than community pharmacists and, 


\section{American Journal of Pharmaceutical Education 2016; 80 (7) Article 117.}

for the most part, hospital pharmacists. Among the academic pharmacy career paths explored, pharmacy practice faculty members with residency training accumulate the highest incomes over their careers, followed by pharmacology faculty members. Although under study conditions, projected academic pharmacy salary levels do not exceed those of community pharmacy in most cases, the academic environment offers other valuable tangible and intangible benefits, including greater flexibility, autonomy, job security, a more diverse workload, tuition reimbursement/reduction, and better fringe benefits, that may offset income differences. Thus, when assessing academic pharmacy as a career option, a more holistic approach - rather than only an economic evaluationshould be considered.

\section{REFERENCES}

1. Doucette WR, Gaither CA, Kreling DH, Mott DA, Schommer JC. 2009 National Pharmacist Workforce Survey. Pharmacy Manpower Project, Inc. 2010. http://www.aacp.org/resources/ research/pharmacyworkforcecenter/Documents/2009\% 20NPWS\%20Executive\%20Summary.pdf. Accessed February 20, 2015.

2. APhA Career Pathway Evaluation Program. http://www.pharmacist. com/sites/default/files/files/Pathway_Briefing_Document.pdf. Accessed February 10, 2015.

3. AACP Pharmacy Career Information. http://www.aacp.org/ resources/student/pharmacyforyou/pharmacycareerinfo/pages/ default.aspx. Accessed February 10, 2015.

4. Pharmacy career information: academic pharmacy. American Association of Colleges of Pharmacy. http://www.aacp.org/ resources/student/pharmacyforyou/pharmacycareerinfo/Documents/ careeroverview.pdf. Accessed February 10, 2015.

5. Sheaffer EA, Brown BK, Byrd DC, et al. Variables impacting an academic pharmacy career choice. Am J Pharm Educ. 2008;72(3): Article 49.

6. Cobaugh DJ. Academia: a rewarding and critically important career path. Am J Health Syst Pharm. 2005;62(11):1204.

7. Academic Pharmacy's Vital Statistics. American Association of Colleges of Pharmacy. http://www.aacp.org/about/pages/vitalstats. aspx. Accessed February 15, 2015.

8. Brown DL. A looming joblessness crisis for new pharmacy graduates and the implications it holds for the Academy. Am J Pharm Educ. 2013;77(5):Article 90.

9. Accreditation Council for Pharmacy Education. Standards revision 2016. https://www.acpe-accredit.org/deans/

StandardsRevision.asp. Accessed September 10, 2015.

10. LeClaire J. Faculty shortage calls some pharmacists back to school. 2009. http://allhealthcare.monster.com/training/articles/ 2977-faculty-shortage-calls-some-pharmacists-back-to-school? page $=1$. Accessed February 20, 2015.

11. U.S. Bureau of Labor Statistics. Occupational employment and wages, May 2015. 29-1051 Pharmacists. http://www.bls.gov/oes/ current/oes291051.htm. Accessed February 25, 2015.

12. 2014-15 Profile of Pharmacy Faculty. American Association of Colleges of Pharmacy. 2015. http://www.aacp.org/RESOURCES/

RESEARCH/INSTITUTIONALRESEARCH/Pages/salarydata.aspx. Accessed February 20, 2015.
13. Hagemeier NE, Murawski MM. Economic analysis of earning a $\mathrm{PhD}$ degree after completion of a PharmD degree. Am J Pharm Educ. 2011;75(1):Article 15.

14. US Social Security Administration. Retirement planner: benefits by year of birth. http://www.socialsecurity.gov/retire2/agereduction. htm. Accessed August 29, 2014.

15. Chisholm-Burns MA, Gatwood J, Spivey CA. Economic analysis of obtaining a PharmD degree and career as a pharmacist. Am J Pharm Educ. 2015;79(8): Article 117.

16. 2014 Directory of Residencies, Fellowships, and Graduate Programs. Lenexa, KS: American College of Clinical Pharmacy; 2014.

17. American Association of College s of Pharmacy. 2012-2013 Profile of Pharmacy Faculty. Alexandria, VA; 2013.

http://www.aacp.org/RESOURCES/RESEARCH/

INSTITUTIONALRESEARCH/Pages/salarydata.aspx.

Accessed September 12, 2016.

18. Office of Extramural Research. Ruth L. Kirchstein National Research Service Award. National Institutes of Health. Bethesda, MD. https://researchtraining.nih.gov/programs/training-grants/T32. Accessed February 20, 2015.

19. Carnevale AP, Cheah B, Strohl J. Hard times: college majors, unemployment and earnings: not all college degrees are created equal. Washington, DC: Georgetown University Center on Education and the Workforce; 2012. http://cew.georgetown.edu/unemployment. Accessed August 18, 2014.

20. Latest cost-of-living adjustment. US Social Security

Administration. Baltimore, MD; 2013. http://www.ssa.gov/oact/cola/ latestCOLA.html. Accessed August 18, 2014.

21. Digest of education statistics, 2012. US Department of Education. http://nces.ed.gov/programs/digest/d12/tables/dt12_381. asp. Accessed August 18, 2014.

22. Trend Data. Tuition Trends, 2004-2012. American Association of Colleges of Pharmacy. Alexandria, VA; 2014. http://test.aacp.org/ resources/research/institutionalresearch/Pages/TrendData.aspx. Accessed September 12, 2016.

23. 2012 graduating student survey. American Association of Colleges of Pharmacy. http://www.aacp.org/resources/research/ institutionalresearch/Pages/GraduatingStudentSurvey.aspx.

Accessed August 18, 2014.

24. Institute for College Access \& Success. Student debt and the Class of 2012. http://projectonstudentdebt.org/state_by_state-data. php. Accessed August 18, 2014.

25. Subsidized and unsubsidized loans. Federal Student Aid. U.S. Department of Education. https://studentaid.ed.gov/sa/ types/loans/subsidized-unsubsidized. Accessed September $12,2016$.

26. Best healthcare jobs. Pharmacist. US News \& World Report. http://money.usnews.com/careers/best-jobs/pharmacist. Accessed September 2, 2014.

27. The rising cost of not going to college. Pew Research Center. Washington, DC: Pew Research Center's Social \& Demographic Trends; 2014. http://www.pewsocialtrends.org/2014/02/11/ the-rising-cost-of-not-going-to-college/. Accessed August 18, 2014.

28. Labor Force Statistics from the Current Population Survey: unemployed persons by occupation, industry, and duration of unemployment. US Bureau of Labor Statistics. http://www. bls.gov/cps/aa2012/cpsaat32.htm. Accessed August 18, 2014. 29. Table 1. PharmD degree programs anticipated for 2014-15. American Association of Colleges of Pharmacy. http://www. 


\section{American Journal of Pharmaceutical Education 2016; 80 (7) Article 117.}

aacp.org/resources/student/pharmacyforyou/admissions/ admissionrequirements/Documents/Table\%201\%20PSAR1415-tables.pdf. Accessed August 18, 2014.

30. How to repay your loans. Federal Student Aid. US Department of Education. https://studentaid.ed.gov/repay-loans/understand/plans/ income-driven. Accessed April 30, 2015.

31. Federal Student Aid. Deferment and Forbearance. US

Department of Education. Washington, DC. https://studentaid.ed. gov/sa/repay-loans/deferment-forbearance. Accessed September 12, 2016.
32. Academia: Clinical Practice. http://www.pharmacist.com/sites/ default/files/files/Profile_01_Academia_Clinical_Practice_SDS_ FINAL_083007.pdf. Accessed March 7, 2015.

33. Schommer JC, Brown LM, Sogol EM. Work profiles identified from the 2007 pharmacist and pharmaceutical scientist career pathway profile survey. Am J Pharm Educ. 2008;72(1): Article 2.

34. Draugalis JR, DiPiro JT, Zeolla MM, Schwinghammer TL. A career in academic pharmacy: opportunities, challenges, and rewards. Am J Pharm Educ. 2006;70(1):Article 17. 